\title{
Substrate Integrated Waveguide Leaky-Wave Antenna Conforming to Conical Shape Surface
}

\author{
W. N. Huang, ${ }^{1}$ Y. J. Cheng, ${ }^{1,2}$ and H. Deng' \\ ${ }^{1}$ Fundamental Science on Extreme High Frequency Laboratory, School of Electronic Engineering, \\ University of Electronic Science and Technology of China, Chengdu 611731, China \\ ${ }^{2}$ State Key Laboratory of Millimeter Waves, Southeast University, Nanjing 210096, China \\ Correspondence should be addressed to Y. J. Cheng; yjcheng@emfield.org
}

Received 28 August 2014; Accepted 22 October 2014

Academic Editor: Guo Qing Luo

Copyright (C) 2015 W. N. Huang et al. This is an open access article distributed under the Creative Commons Attribution License, which permits unrestricted use, distribution, and reproduction in any medium, provided the original work is properly cited.

\begin{abstract}
A conical conformal leaky-wave antenna based on substrate integrated waveguide (SIW) technology is proposed and demonstrated in this paper. This antenna conforms to a conical shape surface with the angle of $40^{\circ}$. It has a narrow beam that scans from $80^{\circ}$ to $97^{\circ}$ with varying frequency $(34 \mathrm{GHz} 37 \mathrm{GHz})$. Both conformal and nonconformal antennas are fabricated through the standard PCB process. Their performances are compared within the desired frequency.
\end{abstract}

\section{Introduction}

Conformal antennas have been of wide interest to scholars due to the purpose of integrating with the structures such as part of airplane, train, or other vehicles. The theory and design of conformal antennas are fully described in [1]. Different surfaces can be used in conformal antennas, such as a cylindrical shape, a conical shape, and a spherical shape. Among them, the conical shape surface can be of special interest for applications in the noses of missile, aircraft, and instrument.

As is well known, leaky-wave antennas are a member of the family of traveling-wave antennas that permit the power leaking along one of their sides, and the radiation patterns can be scanned by varying frequency [2]. Many researchers have studied numerous types of leaky-wave antennas. The leaky-wave antenna in [3] generates leakage when the period length between the vias is sufficiently large. A leaky-wave antenna based on the half-mode substrate integrated waveguide (HMSIW) discussed in [4] possesses the qualities of compact size, wide bandwidth, and quasi-omnidirectional radiation pattern. The long slot leaky-wave antenna [5] has the controllable side lobe level by changing the position of vias in its sidewall. A microstrip leaky-wave antenna (MLWA) performance on a curved surface [6] provides an alternative to the traditional resonant microstrip antennas. A fixedfrequency beam-scanning MLWA array [7] has the capability of scanning the main lobe continuously at the fixed frequency by controlling the relative phase between two elements. An HMSIW leaky-wave antenna with a series of $\pm 45^{\circ}$ slots published in [8] can provide four states of polarization (linear or circular) according to the different input ports. A novel leaky-wave antenna with transverse slots is proposed in [9] that has the advantage of scanning to endfire. It radiates from a periodic set of transverse slots on the top of the substrate. The leaky-wave antenna designed on a composite right/left-handed (CRLH) SIW [10] has beam scanning from the backward to the forward direction and operates in two frequency bands. A low temperature cofired ceramic (LTCC) leaky-wave antenna based on the substrate integrated image guide (SIIG) is realized in [11], and it has both the simplicity in designing procedures and better fabrication reliability.

The conformal leaky-wave antenna has a simple structure, high efficiency, and ability of frequency scanning. Therefore, some useful conformal leaky-wave antennas have been introduced. The cylindrical microstrip leaky-wave antennas implemented in [12] have the high gain and wide bandwidth, similar to those of the planar ones. A novel theory to analyze and design tapered conformal leaky-wave antennas [13] shows how it can maintain the desired high-directive 
scanning performance in spite of the curved shape. By comparing among the nontapered rectilinear antenna, nontapered conformal antenna, and the tapered conformal antenna [14], it presents how the antenna width needs to be tapered along the antenna length to properly synthesize the complex propagation constant and therefore to produce a desired radiation pattern.

As a new guided-wave structure, substrate integrated waveguide (SIW) has attractive advantages including low loss, low cost, easy fabrication, and convenient integration with planar circuit [15-17]. Meanwhile, SIW has the good conformability and full-closed topology to avoid the unwanted leakage, which is a great impetus for the deployment of millimeter-wave integrated conformal array antennas [18]. In this work, a SIW leaky-wave antenna conforming to a conical shape surface with the angle of $40^{\circ}$ is introduced. It is fed by the standard WR-28 waveguide. The antenna is designed and simulated using the full-wave simulation software Ansoft HFSS. S-parameter and radiation patterns are also investigated. The experimental results agree well with simulations.

\section{Conformal SIW Leaky-Wave Antenna Design}

The prototype SIW leaky-wave antenna is shown in Figure 1(a). The antenna leaks power through the SIW side wall by changing the window gap $p$ [3]. This antenna is embedded in a conical base as shown in Figure 1(b). The conformal cone has the angle of $\theta_{c}=40^{\circ}$; the conformal beam direction is in the $x$ oy plane $\left(\right.$ about theta $=90^{\circ}$ ). To realize this, the leaky-wave antenna should has the beam direction of $\theta_{0}=130^{\circ}$ (the angle between the $z$-axis and the beam direction in Figure 1(a)). Here, the antenna radiates at the backward direction.

Firstly, the leaky-wave antenna will be designed. The substrate used here is the Rogers 5880 substrate with the thickness of $1.575 \mathrm{~mm}$, the relative permittivity of 2.2 , and the loss tangent of 0.0009 . The main parameters of the leaky-wave antenna are the SIW width, $l_{1}$, the distance between the leakywave part and the edge of the substrate, $l_{2}$, the length of the leaky-wave part, $l_{3}$, and the leaky-wave window gap, $p=l_{3} / n$, where $n$ is the number of windows. The designed frequency is at $35 \mathrm{GHz}$.

The complex propagation constant of the leaky-wave antenna is

$$
k=\beta-j \alpha
$$

where $\alpha$ is the leakage rate and $\beta$ is the leaky-mode phase constant. The beam direction of the leaky-wave antenna mainly depends on $\beta$ [2]. Consider

$$
\sin \theta_{m}=\frac{\beta}{k_{0}}
$$

In (2), $\theta_{m}=\theta_{0}-90^{\circ}$. The desired beam direction can be realized when changing $\beta$ appropriately. The radiation efficiency

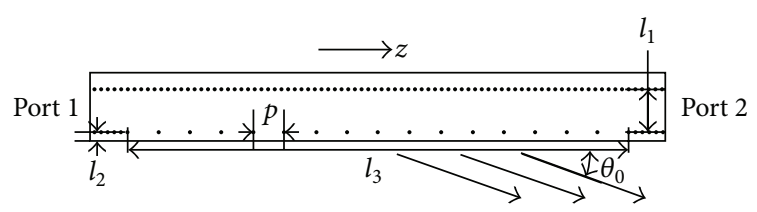

(a)

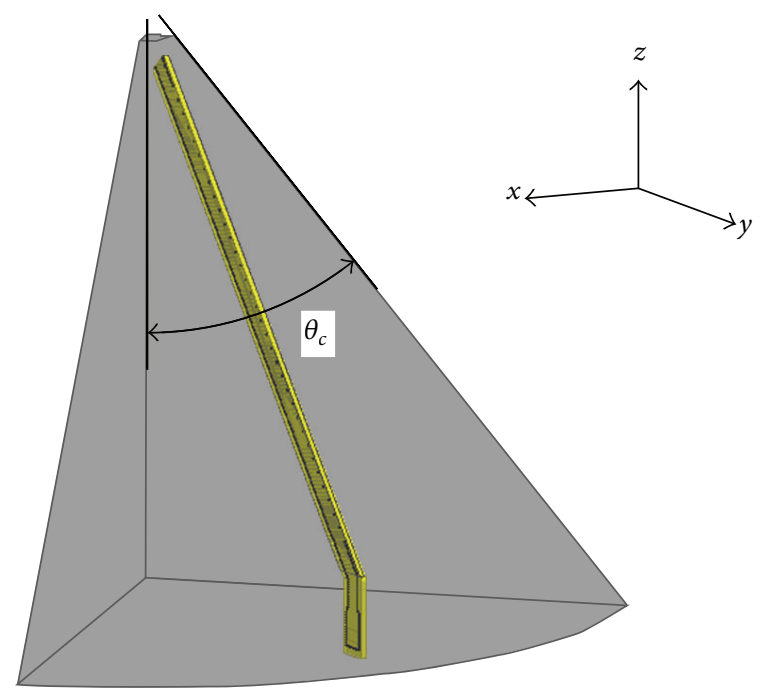

(b)

FIGURE 1: (a) Configuration of the SIW leaky-wave antenna. (b) Configuration of the conformal SIW leaky-wave antenna.

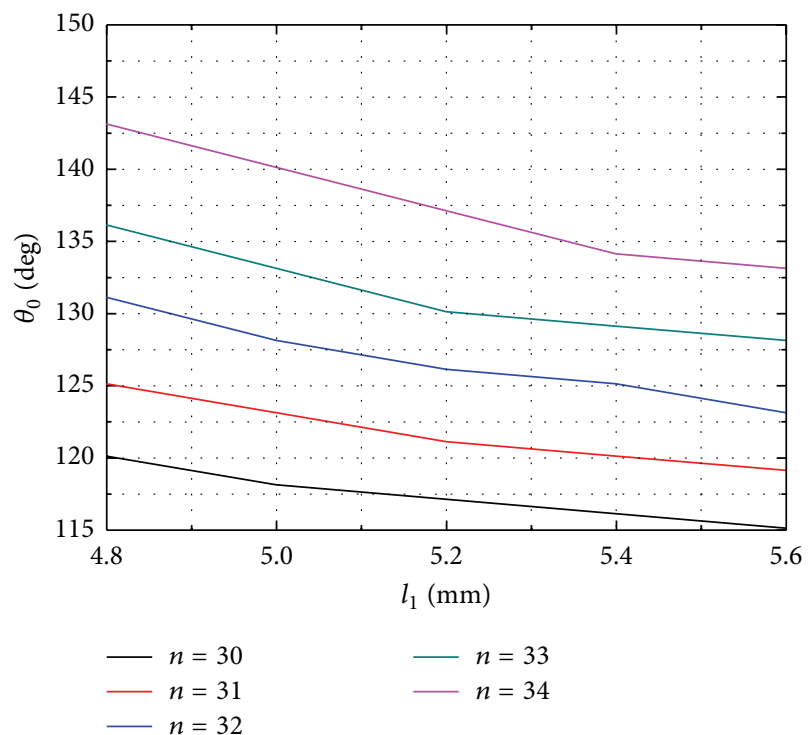

FIgURE 2: The window gap $p=l_{3} / n$ versus beam direction $\theta_{0}$.

due to the absorbed load directly depends on the normalized leakage rate $\alpha / k_{0}$ and the leaky-wave part length $l_{3}$

$$
e^{r}=1-e^{-2 \alpha l_{3}}=1-e^{-4 \pi\left(\alpha / k_{0}\right)\left(l_{3} / \lambda_{0}\right)} .
$$

A typical choice for the radiation efficiency is $90 \%$.

For the proposed antenna, $\alpha$ and $\beta$ can be easily controlled by changing the parameters $l_{1}$ and $p$. Figures $2,3,4$, 


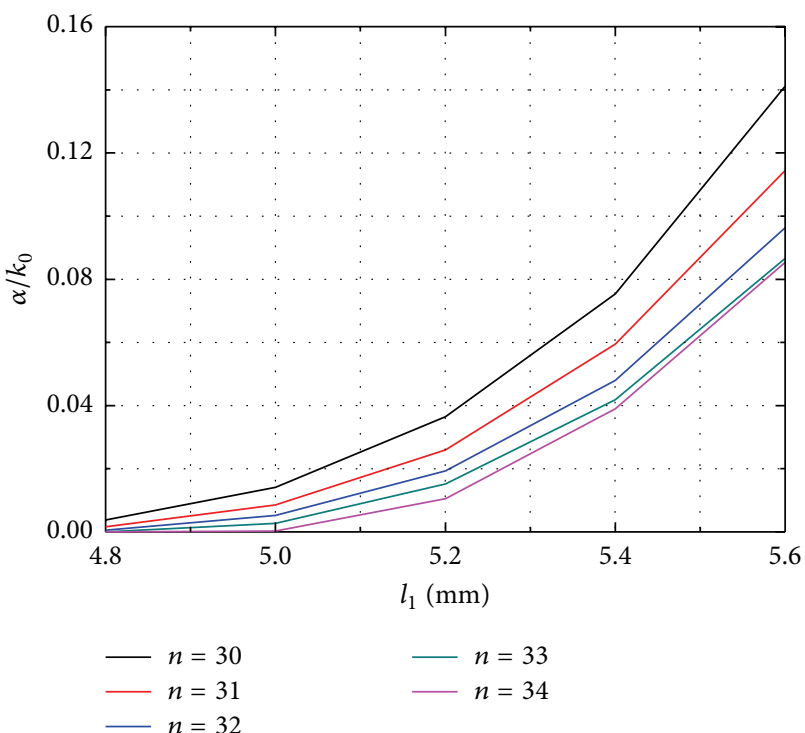

FIgURE 3: The window gap $p=l_{3} / n$ versus normalized leakage rate $\alpha / k_{0}$.

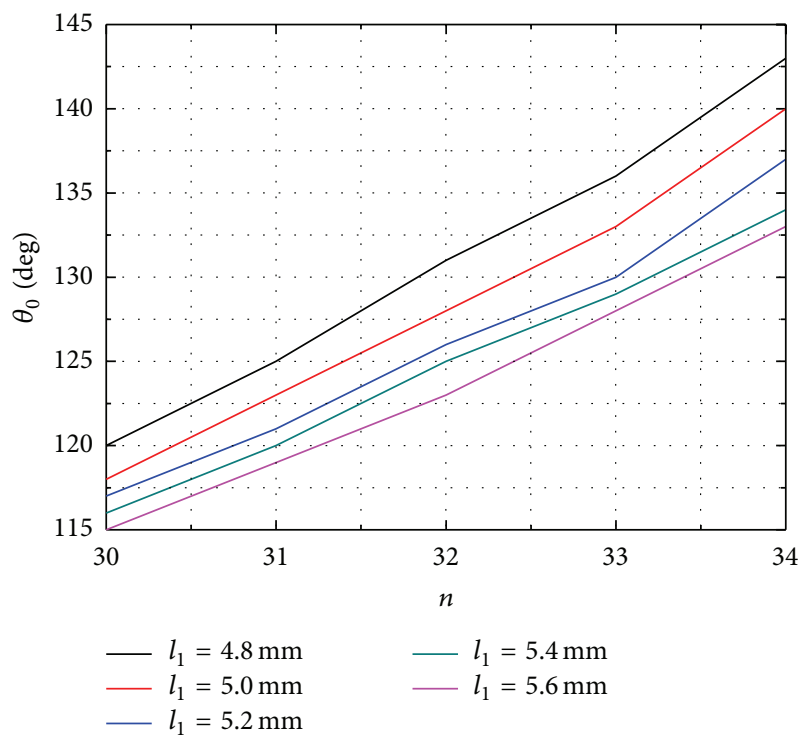

FIgURE 4: The SIW width $l_{1}$ versus beam direction $\theta_{0}$.

and 5 show the performances of $\alpha / k_{0}$ and $\theta_{0}$ when $p$ and $l_{1}$ are varied. In order to avoid the appearance of undesired channel modes, $l_{2}$ is usually set to less than $\lambda / 4$ [2]. The length $l_{3}$ mainly influences the radiation efficiency due to the absorbed load. The relationship between $l_{3}$ and radiation efficiency is listed in Table 1.

To synthesize the desired radiation properties, we finally choose the parameters of leaky-wave antenna as follows: $l_{1}=$ $5.2 \mathrm{~mm}, l_{2}=1 \mathrm{~mm}, l_{3}=150 \mathrm{~mm}$, and $p=4.54 \mathrm{~mm}(n=$ 33). The beam direction of single antenna is $130^{\circ}$. As shown in Figure $6, S_{21}$ of such a two-port antenna is below $-13 \mathrm{~dB}$ within 34 37 GHz. Considering 95\% energy leaking along

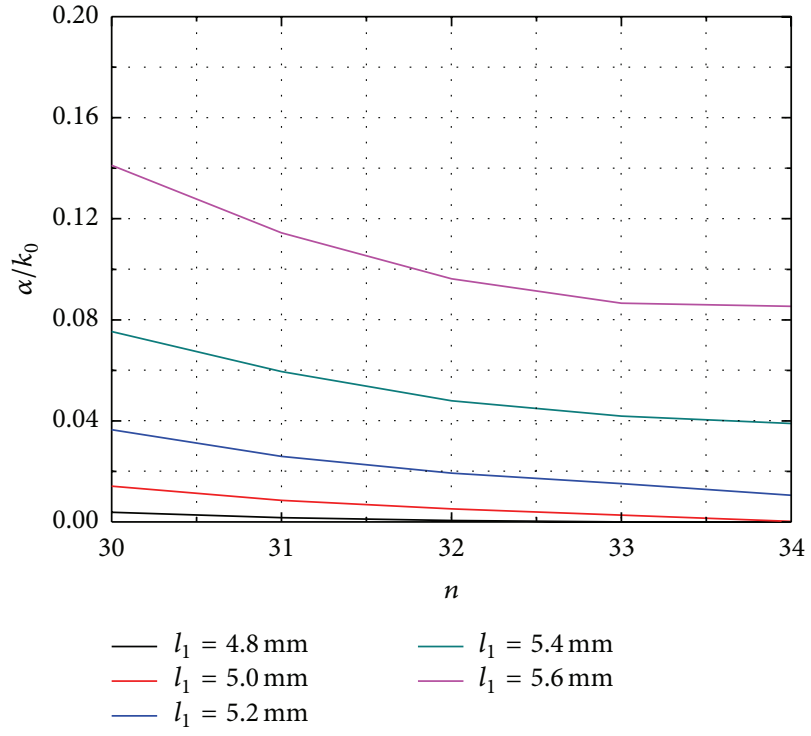

FIGURE 5: The SIW width $l_{1}$ versus normalized leakage rate $\alpha / k_{0}$.

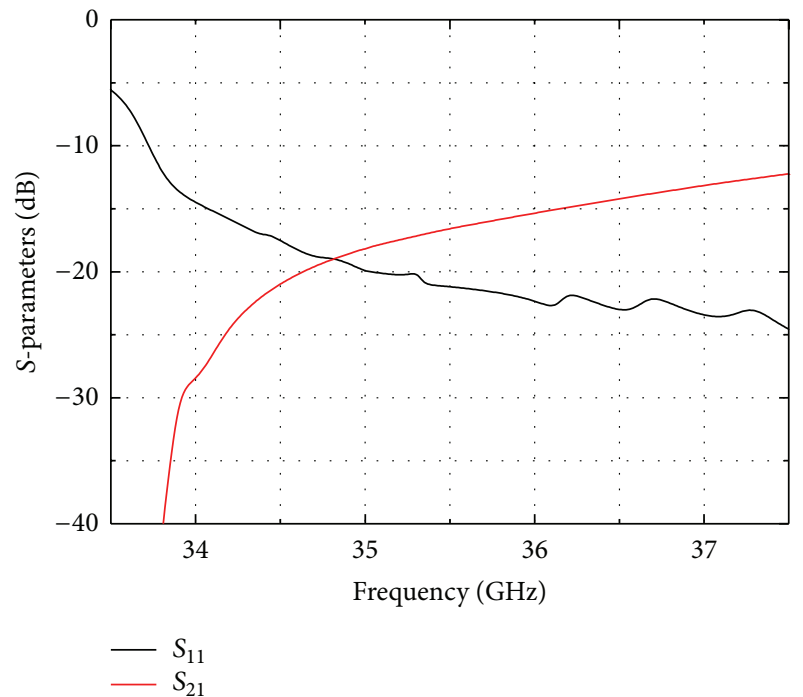

FIGURE 6: Simulated $S$-parameter of the designed two-port leakywave antenna.

TABLE 1: Length $l_{3}$ versus radiation efficiency.

\begin{tabular}{lc}
\hline Length $l_{3}(\mathrm{~mm})$ & Radiation efficiency $(\%)$ \\
\hline 80 & 84.5 \\
100 & 88.9 \\
150 & 93.2 \\
200 & 94.4 \\
\hline
\end{tabular}

SIW, only one port architecture is used in the later simulation and fabrication.

The designed one-port leaky-wave antenna is conformed to the cone. A long groove is cut on the surface of cone, and the antenna is inserted into the groove. The $S$-parameter and radiation patterns of the conformal and nonconformal 


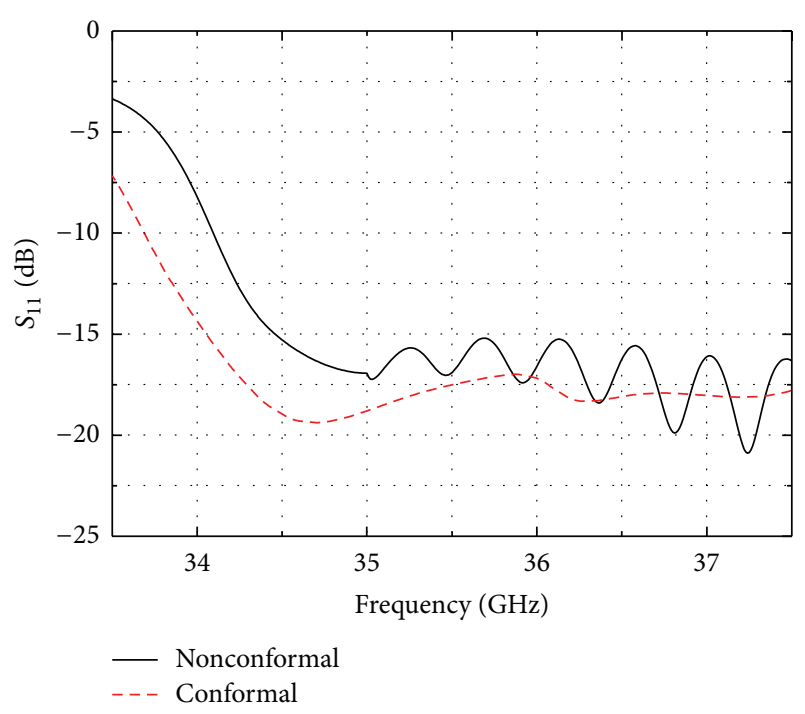

FIGURE 7: Simulated $S$-parameter of the designed conformal and nonconformal one-port antenna.

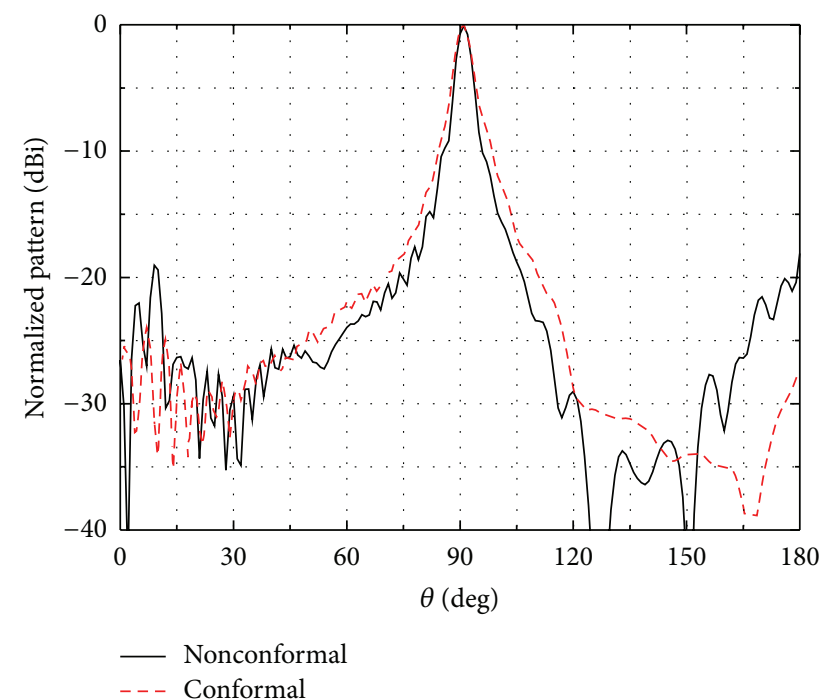

FIGURE 8: Simulated radiation pattern of the designed conformal and nonconformal antenna in the elevation plane.

antennas are compared in Figures 7, 8, and 9. As shown in Figure 7, their $S_{11}$ are almost below $-10 \mathrm{~dB}$ within 34 $37 \mathrm{GHz}$. The conformal gain ( $15.5 \mathrm{dBi})$ is higher than the nonconformal one $(15.2 \mathrm{dBi})$ because of the secondary reflection after conforming to the cone. Moreover, the conformal beam is wider than the nonconformal one in the azimuth plane.

Figure 10 shows the conformal beam scanned from $80^{\circ}$ to $97^{\circ}$ by varying frequency in the elevation plane. When the frequency is increased, the beam moves to a small theta angle. In the azimuth plane, the beam-width is mostly affected by the conformal geometry. As shown in Figure 11, by decreasing the curvature of conformal cone from $13 \mathrm{~m}^{-1}$ to $10.5 \mathrm{~m}^{-1}$, the $3 \mathrm{~dB}$ beam-width is narrowed from $34.6^{\circ}$ to $31.3^{\circ}$. Meanwhile, the gain increases by $0.5 \mathrm{~dB}$.

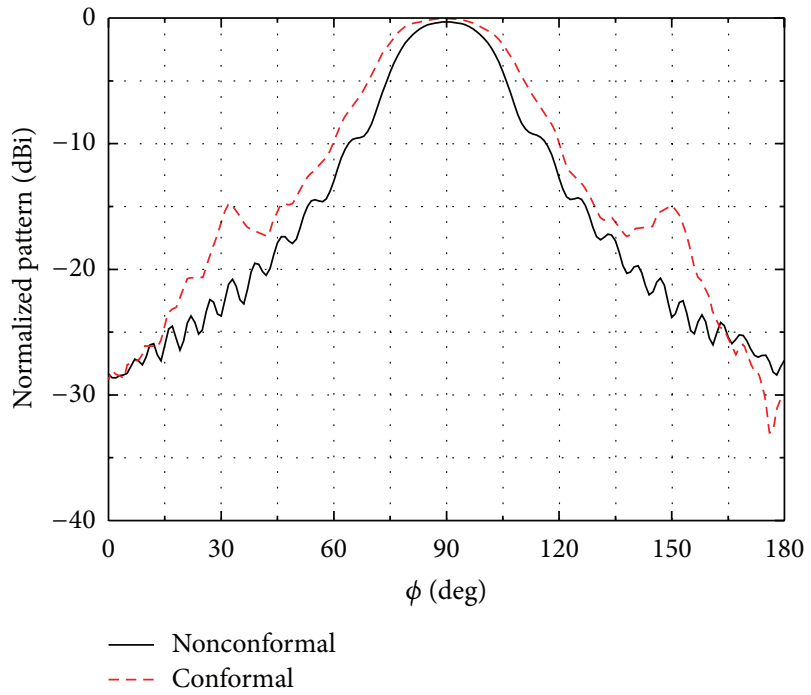

FIGURE 9: Simulated radiation pattern of the designed conformal and nonconformal antenna in the azimuth plane.

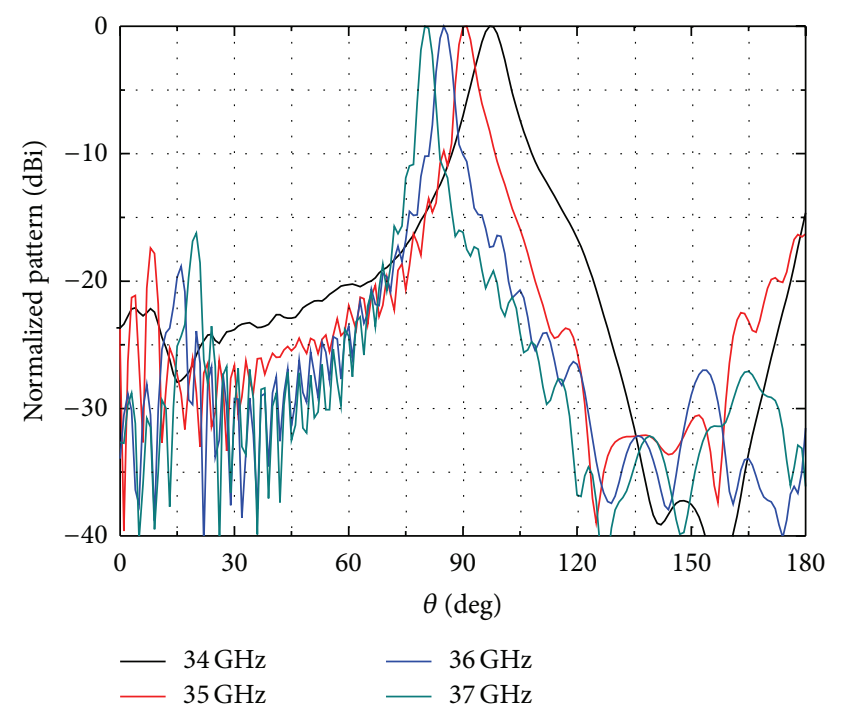

FIGURE 10: Scanned radiation patterns in the elevation plane.

\section{Measurement Results}

A prototype antenna is fabricated to validate our design as shown in Figure 12. The antenna is excited by the standard WR-28 waveguide; the transition between standard waveguide and SIW has the similar configuration as described in [19]. A coupled aperture is etched on the top conductor layer as shown in Figure 12(a). The purpose of the designed corner in Figure 12(a) is to make the excitation vertical to the horizontal plane. The reflection coefficients of the conformal and nonconformal antennas are measured by the network analyzer. As shown in Figure 13, the measured $S$-parameters are almost below $-10 \mathrm{~dB}$ within $34 \sim 37 \mathrm{GHz}$.

The radiation patterns of conformal and nonconformal antennas are measured in a microwave anechoic chamber. As 


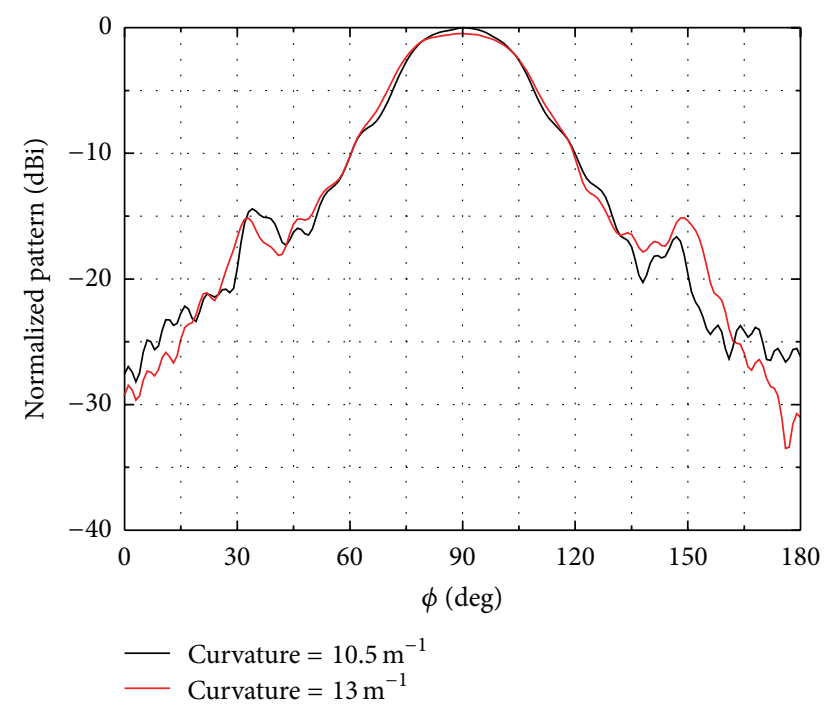

FIGURE 11: Radiation patterns in the azimuth plane by decreasing the curvature.

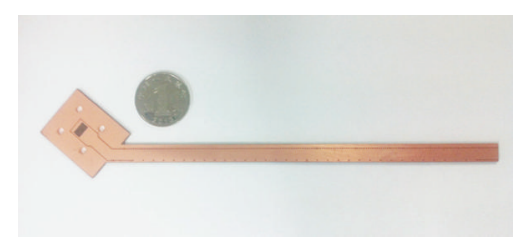

(a)

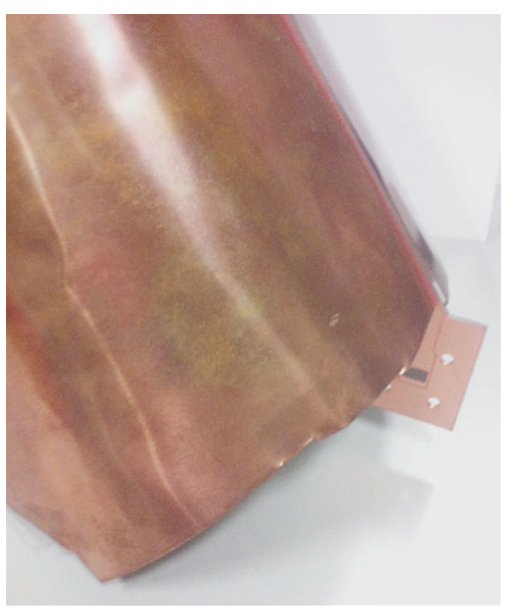

(b)

FIGURE 12: (a) Photograph of the fabricated leaky-wave antenna. (b) Photograph of the fabricated conformal leaky-wave antenna.

shown in Figures 14-15, the measured results have the same trend of the simulated ones.

Then, the radiation patterns of conformal antenna are measured at different frequencies from $34 \mathrm{GHz}$ to $37 \mathrm{GHz}$ as shown in Figure 16. Table 2 summarizes the measured data. In the azimuth plane, it can cover an angular region of $40.9^{\circ}$. The radiation patterns with different conformal curvatures are also measured as the simulation as shown in Figure 17. The $3 \mathrm{~dB}$ beam-width is narrowed with $3.2^{\circ}$.

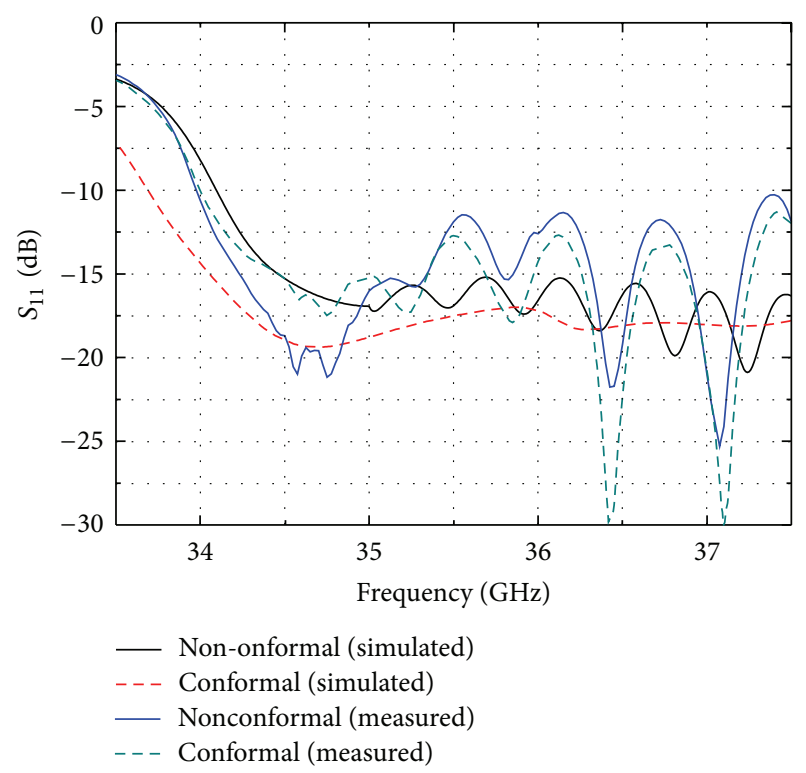

FIGURE 13: Measured S-parameters of the fabricated SIW leaky-wave antennas.

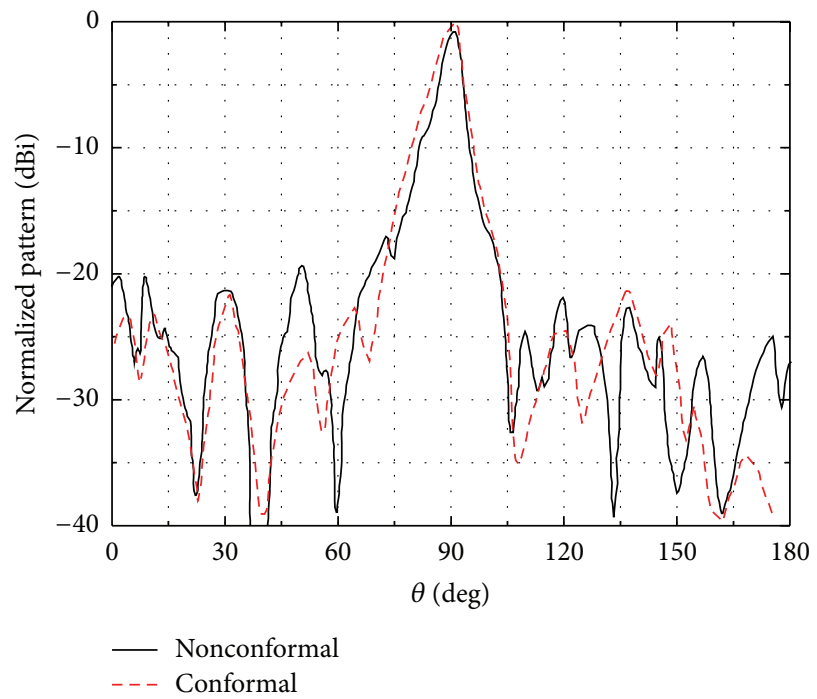

FIGURE 14: Measured radiation pattern in the elevation plane of the fabricated SIW leaky-wave antennas.

TABLE 2: Measurements of antenna at different frequency.

\begin{tabular}{lccc}
\hline $\begin{array}{l}\text { Frequency } \\
(\mathrm{GHz})\end{array}$ & $\begin{array}{l}\text { Simulated } \\
\text { gain }(\mathrm{dBi})\end{array}$ & $\begin{array}{c}\text { Measured } \\
\text { gain }(\mathrm{dBi})\end{array}$ & $\begin{array}{c}\text { Beam } \\
\text { direction }\end{array}$ \\
\hline 34 & 14.95 & 14.38 & $96.5^{\circ}$ \\
35 & 15.5 & 15.55 & $90.7^{\circ}$ \\
36 & 16.35 & 16.13 & $84.1^{\circ}$ \\
37 & 17.36 & 17.07 & $79.6^{\circ}$ \\
\hline
\end{tabular}

\section{Conclusion}

A conical conformal leaky-wave antenna based on the SIW technology is designed and experimented. It presents a wide 


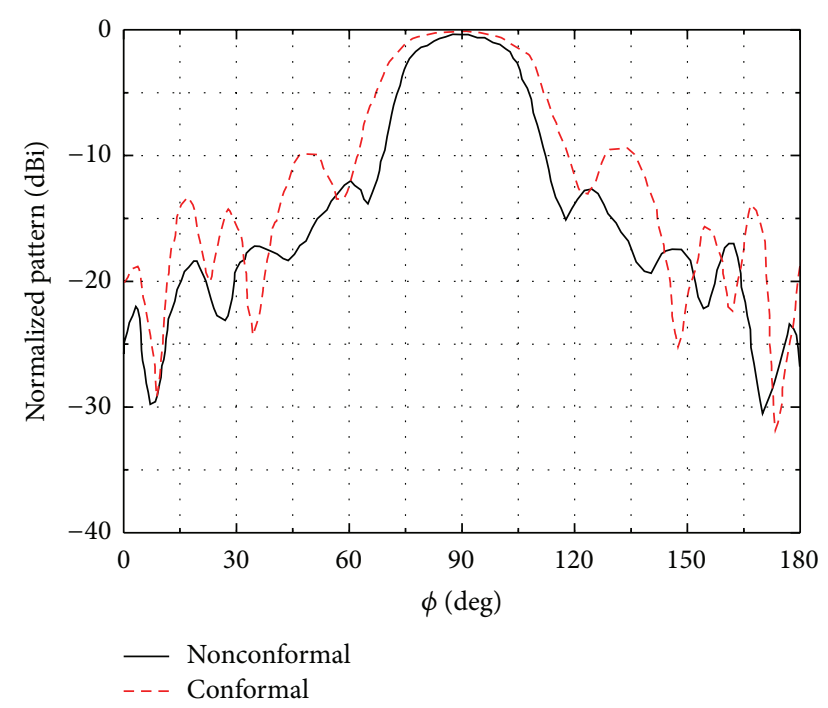

FIGURE 15: Measured radiation pattern in the azimuth plane of the fabricated SIW leaky-wave antennas.

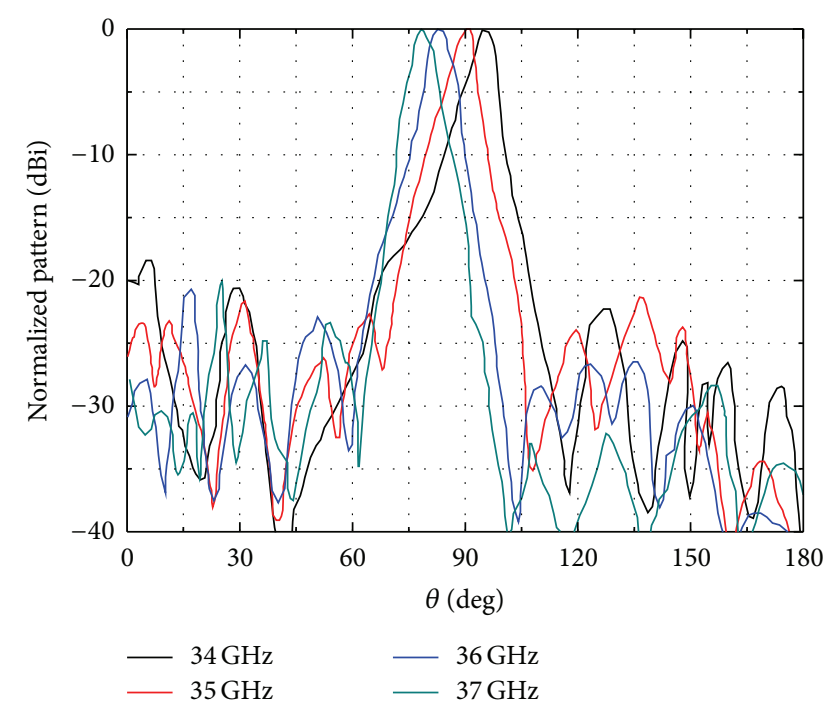

FIGURE 16: Scanned radiation patterns in the elevation plane of the fabricated conformal SIW leaky-wave antenna.

beam-width in the azimuth plane and a narrow beam-width in the elevation plane. This conformal antenna can scan from $80^{\circ}$ to $97^{\circ}$ with varying frequency ( $34 \mathrm{GHz} 37 \mathrm{GHz}$ ). The measured antenna characteristics agree well with the simulations. Besides, the antenna has the advantages of low loss, high efficiency, and simple configuration.

\section{Conflict of Interests}

The authors declare that there is no conflict of interests regarding the publication of this paper.

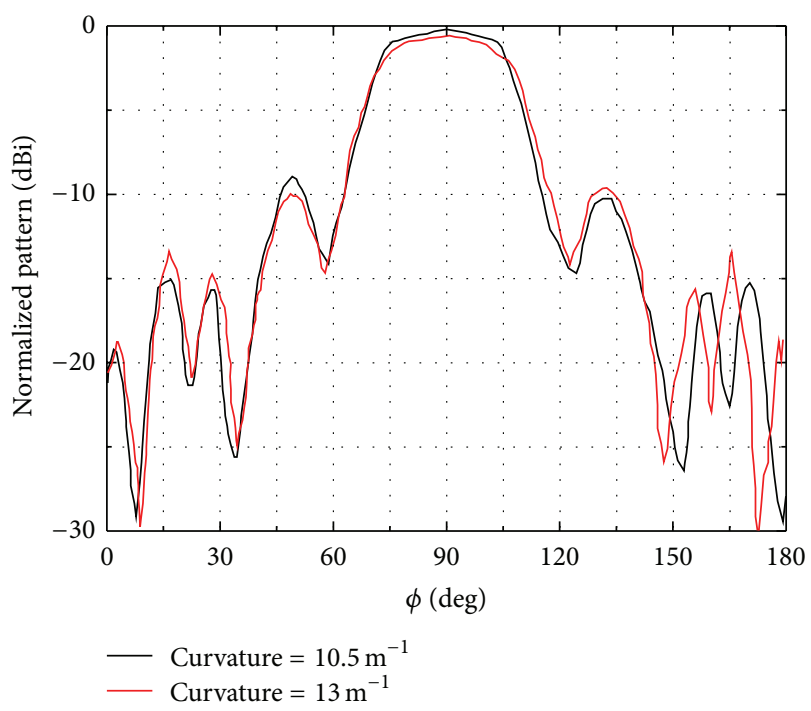

FIGURE 17: Radiation patterns in the azimuth plane of the fabricated conformal SIW leaky-wave antenna by decreasing the curvature.

\section{Acknowledgments}

This work is supported in part by Program for New Century Excellent Talents in University under Grant NCET-13-0089 and by the State Key Laboratory of Millimeter Waves under Grant K201315.

\section{References}

[1] L. Josefsson and P. Persson, Conformal Array Antenna Theory and Design, Wiley-Interscience, Hoboken, NJ, USA, 2006.

[2] A. A. Oliner and D. R. Jackson, "Leaky-wave antennas," in Antenna Engineering Handbook, J. L. Volakis, Ed., chapter 11, Mc-Graw Hill, New York, NY, USA, 4th edition, 2007.

[3] D. Deslandes and K. Wu, "Substrate integrated waveguide leakywave antenna: concept and design considerations," in Proceedings of the Asia-Pacific Microwave Conference (APMC '05), vol. 1, December 2005.

[4] J. Xu, W. Hong, H. Tang, Z. Kuai, and K. Wu, "Half-mode substrate integrated waveguide (HMSIW) leaky-wave antenna for millimeter-wave applications," IEEE Antennas and Wireless Propagation Letters, vol. 7, pp. 85-88, 2008.

[5] Y. J. Cheng, W. Hong, K. Wu, and Y. Fan, "Millimeter-wave substrate integrated waveguide long slot leaky-wave antennas and two-dimensional multibeam applications," IEEE Transactions on Antennas and Propagation, vol. 59, no. 1, pp. 40-47, 2011.

[6] J. Radcliffe, G. Thiele, R. Penno, S. Schneider, and L. Kempel, "Microstrip leaky-wave antenna performance on a curved surface," in Proceedings of the IEEE Antennas and Propagation Society International Symposium (APSURSI '06), pp. 4247-4250, July 2006.

[7] Y. Li, Q. Xue, E. K.-N. Yung, and Y. Long, "A fixed-frequency beam-scanning microstrip leaky wave antenna array," IEEE Antennas and Wireless Propagation Letters, vol. 6, pp. 616-618, 2007.

[8] Y. J. Cheng, W. Hong, and K. Wu, "Millimeter-wave half mode substrate integrated waveguide frequency scanning antenna 
with quadri-polarization," IEEE Transactions on Antennas and Propagation, vol. 58, no. 6, pp. 1848-1855, 2010.

[9] J. Liu, D. R. Jackson, and Y. Long, "Substrate integrated waveguide( SIW) leaky-wave antenna with transverse slots," IEEE Transactions on Antennas and Propagation, vol. 60, no. 1, pp. 20-29, 2012.

[10] J. Machac, M. Polivka, and K. Zemlyakov, "A dual band leaky wave antenna on a CRLH substrate integrated waveguide," IEEE Transactions on Antennas and Propagation, vol. 61, no. 7, pp. 3876-3879, 2013.

[11] Y. J. Cheng, Y. X. Guo, X. Y. Bao, and K. B. Ng, "Millimeter-wave low temperature co-fired ceramic leaky-wave antenna and array based on the substrate integrated image guide technology," IEEE Transactions on Antennas and Propagation, vol. 62, no. 2, pp. 669-676, 2014.

[12] L.-C. Lin, H. Miyagawa, T. Kitazawa, R. B. Hwang, and Y.D. Lin, "Characterization and design of cylindrical microstrip leaky-wave antennas," IEEE Transactions on Antennas and Propagation, vol. 56, no. 7, pp. 1853-1859, 2008.

[13] J. L. Gómez-Tornero, "Analysis and design of conformal tapered leaky-wave antennas," IEEE Antennas and Wireless Propagation Letters, vol. 10, pp. 1068-1071, 2011.

[14] A. J. Martinez-Ros, J. L. Gómez-Tornero, and G. Goussetis, "Conformal tapered microstrip leaky-wave antennas," in Proceedings of the 6th European Conference on Antennas and Propagation (EuCAP '12), pp. 154-158, March 2012.

[15] Y. J. Cheng, P. Chen, W. Hong, T. Djerafi, and K. Wu, "Substrateintegrated-waveguide beamforming networks and multibeam antenna arrays for low-cost satellite and mobile systems," IEEE Antennas and Propagation Magazine, vol. 53, no. 6, pp. 18-30, 2011.

[16] G. Q. Luo, X. H. Zhang, L. X. Dong, W. J. Li, and L. L. Sun, "A gain enhanced cavity backed slot antenna using high order cavity resonance," Journal of Electromagnetic Waves and Applications, vol. 25, no. 8-9, pp. 1273-1279, 2011.

[17] G. Q. Luo, Z. F. Hu, L. X. Dong, and L. L. Sun, "Planar slot antenna backed by substrate integrated waveguide cavity," IEEE Antennas and Wireless Propagation Letters, vol. 7, pp. 236-239, 2008.

[18] Y. J. Cheng, H. Xu, D. Ma, J. Wu, L. Wang, and Y. Fan, "Millimeter-wave shaped-beam substrate integrated conformal array antenna," IEEE Transactions on Antennas and Propagation, vol. 61, no. 9, pp. 4558-4566, 2013.

[19] Y. J. Cheng, W. Hong, and K. Wu, "94 GHz substrate integrated monopulse antenna array," IEEE Transactions on Antennas and Propagation, vol. 60, no. 1, pp. 121-129, 2012. 

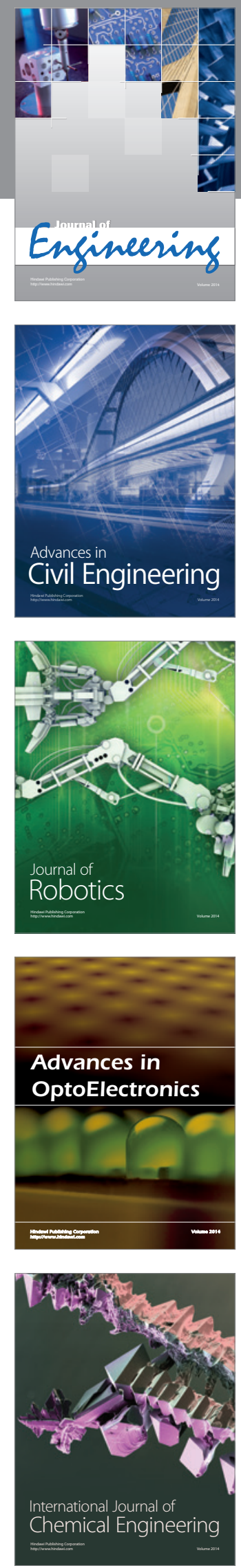

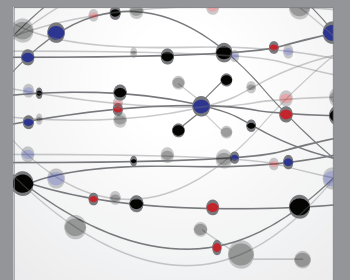

The Scientific World Journal
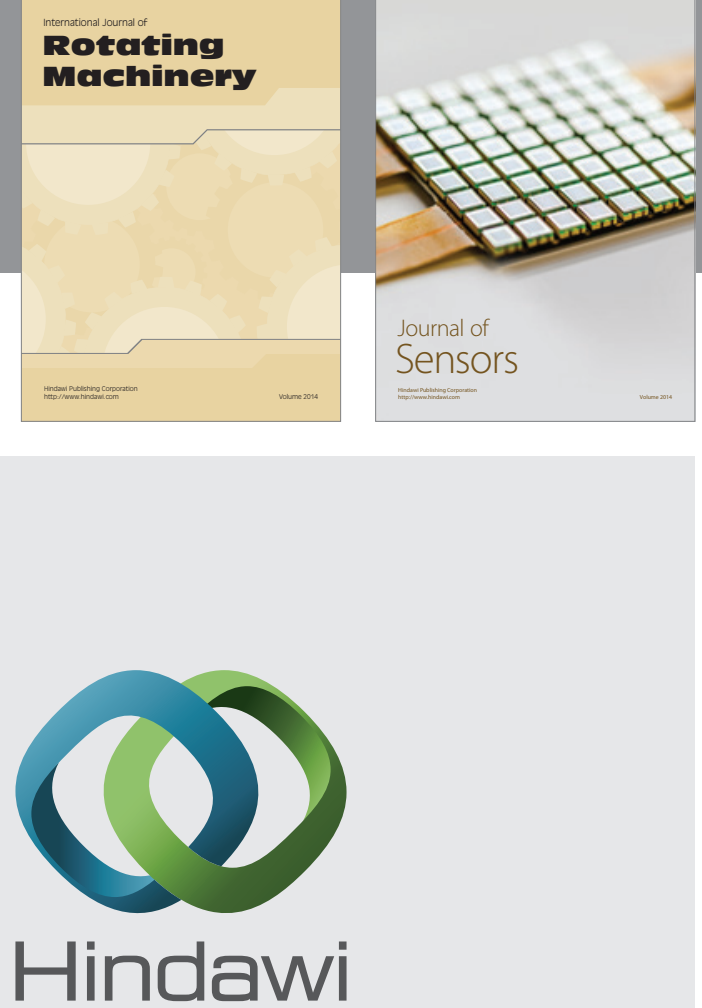

Submit your manuscripts at http://www.hindawi.com
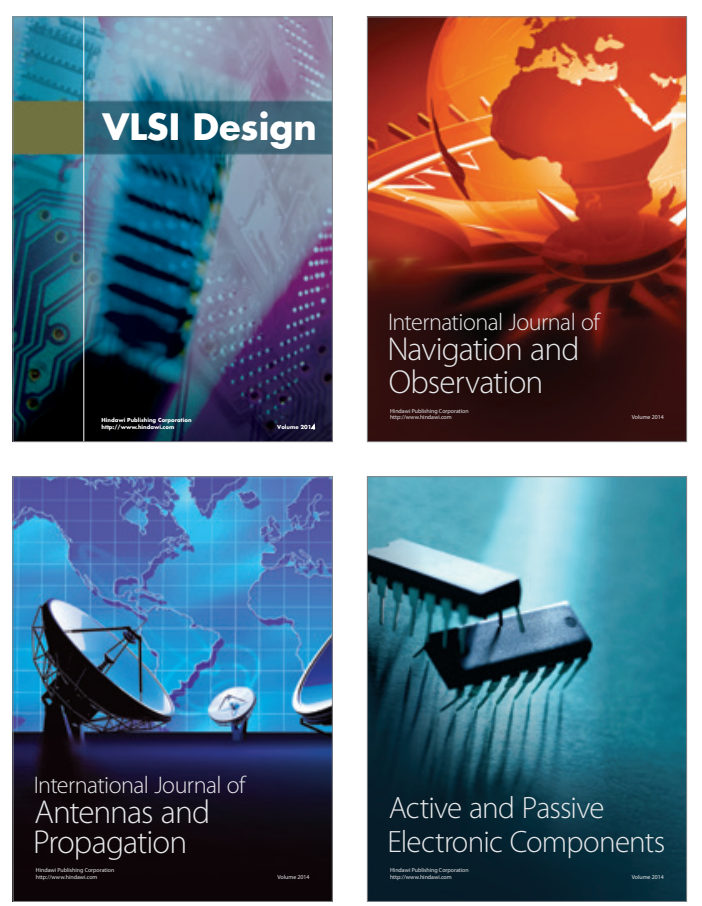
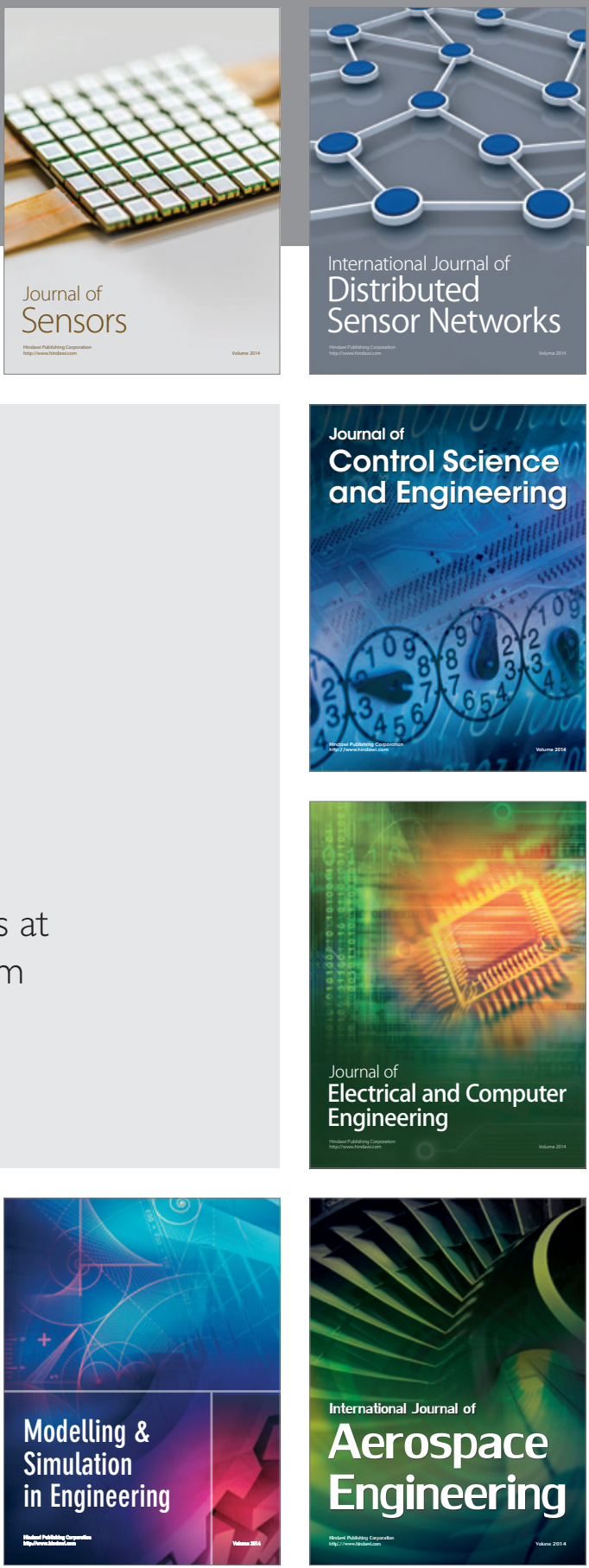

Journal of

Control Science

and Engineering
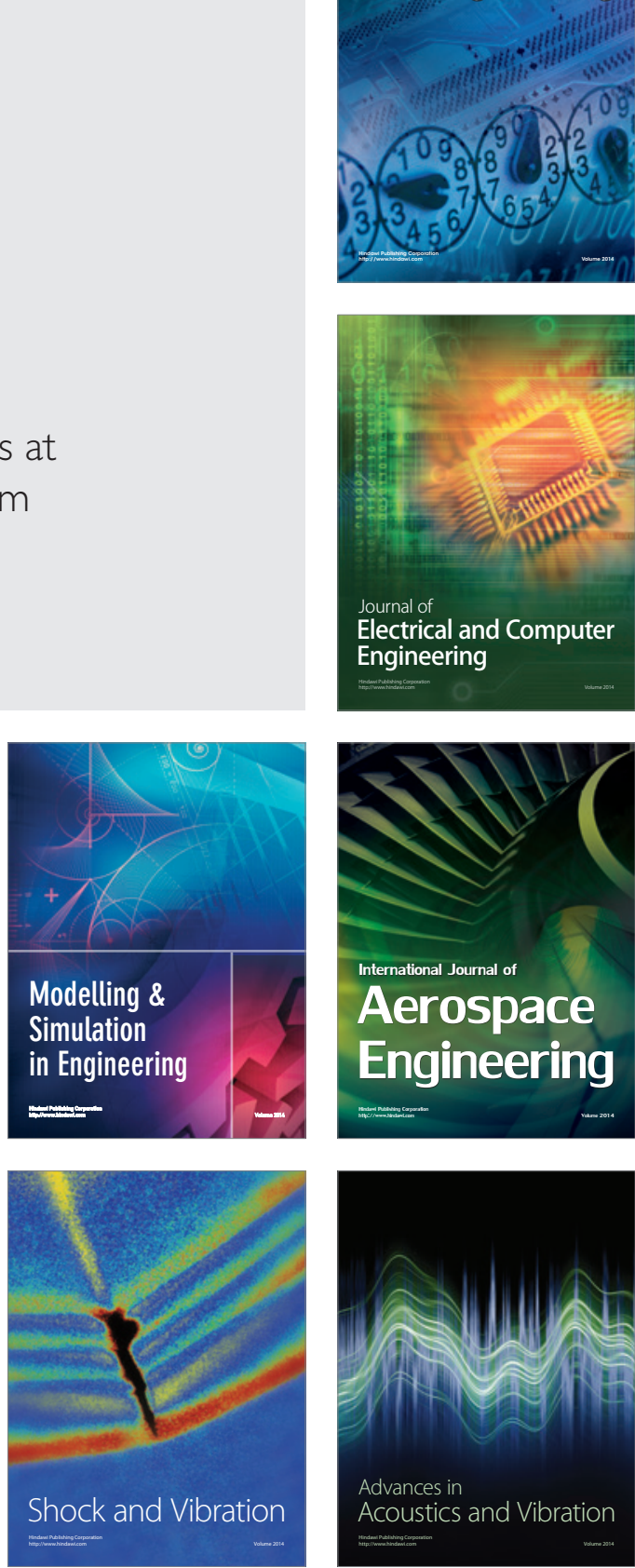